\title{
Future water availability in selected European catchments: a probabilistic assessment of seasonal flows under the IPCC A1B emission scenario using response surfaces
}

\author{
M. Weiß ${ }^{1, *}$ \\ ${ }^{1}$ Center for Environmental Systems Research, University of Kassel, Kassel, Germany \\ *now at: KNMI (Royal Netherlands Meteorological Institute), De Bilt, The Netherlands
}

Received: 25 January 2010 - Revised: 20 June 2011 - Accepted: 7 July 2011 - Published: 4 August 2011

\begin{abstract}
A grid-based water balance model is used to quantify exceedance probabilities of high and low stream flow thresholds, and analyse their progression over the course of the 21 st century. The analysis is carried out for 18 European river basins using the response surface method in combination with probabilistic projections of climate change, conditional to the IPCC A1B emission scenario up to 2100. According to this study, Nordic basins have the highest probability of high flow threshold violation in Europe, while in Central and Southern European basins, the probability of low flow threshold violation is highest. While the high flow violation occurs mostly during winter, with other seasons being likewise probable, low flow violation only occurs in summer. Some basins are facing an increased stream flow amplitude, having high probabilities for both, high flow and low flow violations.
\end{abstract}

\section{Introduction}

The hydrological water cycle plays a central role in the climate, ecology, and biogeochemistry of the planet (Vörösmarty and Sahagian, 2000). The growing awareness of an anthropogenic-induced climate change raises the question of its impact on the terrestrial water cycle. Increasing evidence of potential disturbances of the land-based water cycle is found by numerous studies examining the impacts of climate change on hydrology and water resources. Starting from sub-catchment and catchment studies, there is a tendency to broaden the spatial scale of analysis towards

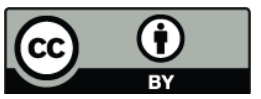

Correspondence to: $\mathrm{M}$. Weiß (weiss@knmi.nl) cross-country, continental or global studies (aus der Beek et al., 2011; Dankers and Feyen, 2009; Lehner et al., 2006; Bergström et al., 2001; Mimikou et al., 2000; Arnell, 1998).

In the past, hydrological impact assessments of climate change have mostly been based on alternative but equally likely greenhouse gas emission scenarios, which are used in climate model experiments to generate climate scenarios (UKCP09, Murphy et al., 2009; Fourth Assessment Report, IPCC, 2007; Special Report on Emission Scenarios, IPCC, 2000). Projected climate changes are then fed into a hydrological impact model to analyze the impact on water resources. This approach narrows emission scenarios to follow specific pathways. Herein considered, and to some degree limited, climate change uncertainty comprises uncertainty in anthropogenic forcing (by applying multiple but a finite number of scenarios), and model uncertainty (by using multi-model climate change projections). Sampling a broader range of uncertainty by increasing the number of emission scenarios or increasing the number of considered climate models in the impact analysis is confined by computer power and time because an increasingly number of runs has to be carried out. Hydrological impact studies have therefore solely exploited projections of a very limited number of climate models and emission scenarios, often considering as little as two options (e.g. Alcamo et al., 2007; Lehner et al., 2006).

In order to reduce the uncertainty associated with future climate change projections and at the same time facilitate the comparison between catchments and over larger areas, this study introduces a probabilistic assessment of stream flow responses to climate change by combining impact response surfaces generated with a hydrological simulation model with probability distribution functions of future climate. This approach considers uncertainty associated with

Published by Copernicus Publications on behalf of the European Geosciences Union. 
major known physical, chemical and biological feedbacks of the climate system, while additionally facilitating the tracking and visualization of transient change. The method can theoretically be applied to an arbitrary number of basins, under consideration of a large number of climate projections from different models for different emission scenarios. Here, we demonstrate its application to 18 European river catchments for the IPCC A1B emission scenario.

\section{Materials and methods}

\subsection{Experiment design}

A grid-based conceptual water balance model is used to generate responses of stream flow for a range of possible future climate changes, similar to a sensitivity analysis. These are combined with probabilistic distribution functions of future climate to generate exceedance probabilities of stream flow thresholds for a selection of 18 European river basins (Fig. 1) for the coming century up to 2100 . In the following sections, the different steps are explained in more detail.

In a preceding study, the sensitivity of annual water availability to climate change was analysed in a similar manner (Weiß and Alcamo, 2011). The study showed that stream flow responses exhibited pronounced monthly variability, which is smoothed when analysed on an annual basis, underlining the need for an analysis at higher temporal resolution. High or low flows might be shifted to the subsequent month, e.g. due to changes in the timing of snowmelt. Since a shift in stream flow of several days does not exhibit an acute threat either to society or to ecosystems, this study analyses the impact of climate change on seasonal flows. The seasonality of stream flow varies strongly from river to river. The fast component of the hydrological regime, such as subsurface stormflow, Hortonian overland flow, and interflow, are influenced mostly by the local seasonal dynamics of precipitation and air temperature, which, in combination with soil and vegetation characteristics, determine the evapotranspiration demand. Its slow components, i.e. groundwater fluxes, control the baseflow generation of a river basin and are the dominant driver of low flow river runoff.

\subsection{The WaterGAP model}

Stream flows are computed with the WaterGAP model (Alcamo et al., 2003; Döll et al., 2003), a grid-based global model for the integrated assessment of current and future water availability and water use. All important water storage components are taken into account, i.e. interception, soil water, snow, groundwater and surface water, including lakes and wetlands, and surface runoff, as well as anthropogenic water abstractions in the main water-using sectors.

Simulations of river discharge are forced by a thirty-year period of monthly climate time series from the CRU gridded dataset of monthly precipitation, air temperature, cloud

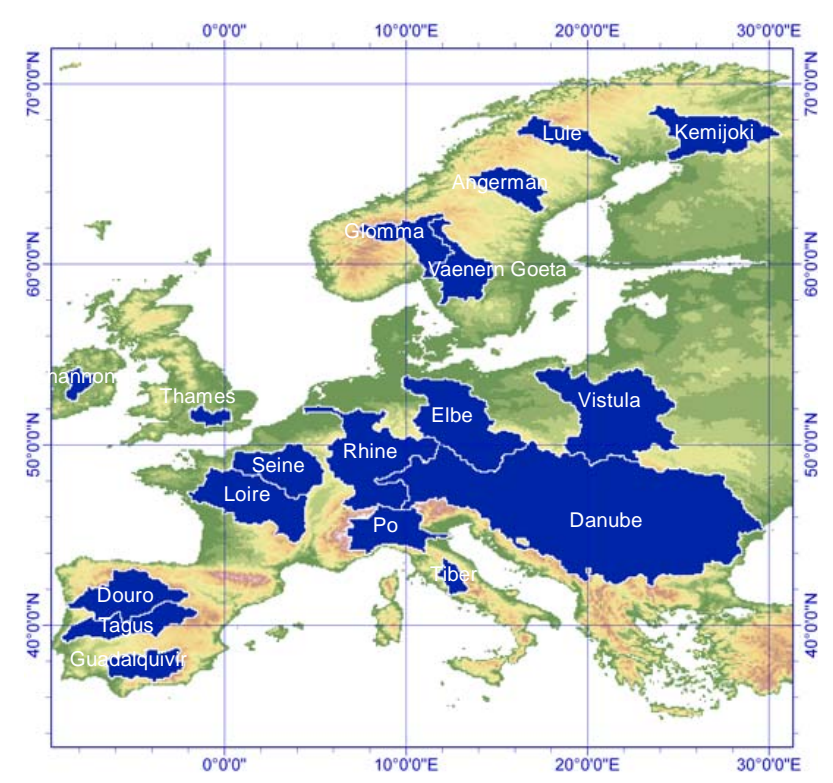

Fig. 1. Location of the 18 analysed European catchments.

cover and wet day frequency (CRU TS 2.1, Mitchell and Jones, 2005), which are disaggregated to daily values with the WaterGAP model (Weiß and Alcamo, 2011). In each model grid cell (at the same equal angle $0.5^{\circ}$ resolution as the input data) the daily vertical and lateral water balances are calculated, quantifying each of their components: evapotranspiration, interception, groundwater storage, surface- and subsurface runoff, and inflow from upstream cells. Hereby, water availability is defined as the total renewable water resource. River discharge (synonymously used to stream flow) is defined as the water availability of a basin reduced by anthropogenic consumptive uses.

The consumptive uses are computed with the water use modules of WaterGAP for the main water consuming sectors: households, industry and agriculture. The domestic sector includes municipal and household uses; the industrial sector is subdivided into water needs for electricity production and water required in the manufacturing process; the agricultural sector is subdivided into irrigation water needs and livestock consumptive uses (Alcamo et al., 2005).

These spatially explicit water uses are abstracted from the water availability in the respective grid cell. The remainder forms river discharge, which is routed through the river basin cells according to a global drainage direction map (Döll and Lehner, 2002). WaterGAP simulations of river discharge have been extensively validated against measured discharges from the Global Runoff Data Centre (GRDC, 2004) at currently 1235 stations world-wide (Weiß and Alcamo, 2011; Alcamo et al., 2003). 


\subsection{Response surfaces}

A response surface (RS) describes the response of a variable $z$ along a range of simultaneous changes in two or more driving variables $x$ and $y$. Here, we create response surfaces for individual catchments that express the response of stream flow in the respective basin to climate change of different magnitudes. Temperature $(T)$ and precipitation $(P)$ are used as driving variables. RS is the result of individual 30-yr model simulations with the WaterGAP model at a daily time step, with a perturbed reference climate in the range of $\Delta T=-1{ }^{\circ} \mathrm{C}$ to $+6{ }^{\circ} \mathrm{C}$, and $\Delta P=-40 \%$ to $+100 \%$. The output of each $30-\mathrm{yr}$ model simulation, consisting of time series of daily river flows, is averaged by season to form a discrete data point in the $3-\mathrm{D}$ response space. These points in their combination are interpolated per seasons to a continuous surface to form the RS.

Since it is well-elaborated that projected climate change is non-uniform throughout the year, i.e seasonally biased (Nikulin et al., 2011; Ballester et al., 2009; Hagemann et al., 2009), monthly scaling factors are calculated, which scale the average reference climate perturbation to a perturbation per month (Fig. 2). Scaling factors are calculated for each model-grid cell based on an average future seasonal cycle (Weiß and Alcamo, 2011) as projected by a number of regional and global climate model simulations under the IPCC A1B scenario from the ENSEMBLES project (Hewitt, 2005).

$\operatorname{Tp}_{c t}=\operatorname{Tref}_{c t}+c \Delta T$

with $\mathrm{Tp}=$ perturbed temperature in grid-cell $c$ at time step $t$, Tref $=$ reference temperature in grid-cell $c$ at time step $t, c=$ scaling factor for monthly climate perturbation and $\Delta T=$ average annual perturbation. $\Delta T=$ is plotted on the $x$ axis of the RS plot.

Temperature of the reference climate is perturbed following Eq. (1). Precipitation is perturbed accordingly, except that the reference precipitation Pref $_{c t}$ is multiplied by $c \Delta P$. See also Weiß and Alcamo (2011) for further details.

Water uses are kept at their 30-yr long-term reference value to explicitly consider climate change impacts. An example of the response surfaces for each of the four seasons, winter (December, January, February), spring (March, April, May), summer (June, July, August), and autumn (September, October, November) is shown in Fig. 3 for the Elbe basin. Stream flow is given as the long-term average of a 30 -yr simulation in $\mathrm{km}^{3} /$ season. Current conditions are found on the RS at the intersection of $0 \%$ change in $P$ and $0{ }^{\circ} \mathrm{C}$ change in $T$.

\subsection{Impact thresholds}

Thresholds are assumed to mark the critical state in a system, beyond which the proper functioning and integrity of the system might not be guaranteed. The probability of exceeding

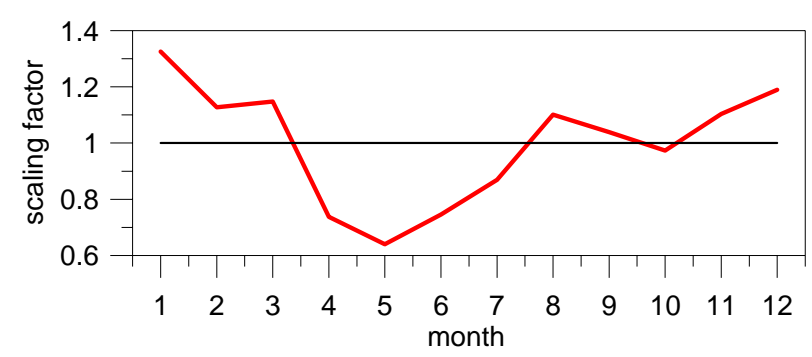

Fig. 2. Monthly scaling factors for the perturbation of the reference temperature time series for a cell in Central Europe based on a projected average change in future seasonal temperature cycle.

a threshold is used here as a measure of the threat imposed on a basin by climate change. The first and foremost visible hydrological impact of climate change is a change in stream flow. Elevated river discharges can cause accelerated erosion rates in the upper reaches and a disturbed sediment delivery in the lower reaches (Middelkoop and Asselman, 2003), increased flow velocities, longer inundation of flood plains and meadows. They are further connected with a higher risk of floods. Low flows, too, affect sediment regime, and flow velocity, but also, for example, water quality and ecosystems or groundwater depletion. Overall, low flow is associated with a reduced amount of water available for anthropogenic and ecosystem uses.

Stream flow thresholds can be based on a wide variety of economical, ecological, chemical or social criteria, for example minimum values required for hydro power generation, industrial cooling, water quality aspects or to maintain a navigable channel, see also Weiß and Alcamo (2011). For this study, two established flow thresholds are analysed: the $Q_{20}$, a high flow threshold, and the $Q_{80}$, a low flow threshold (Monk et al., 2007; Olden and Poff, 2003; Clausen and Biggs, 2000). These values mark the flow that is statistically exceeded $80 \%$ (low flow threshold), or $20 \%$ (high flow threshold) of the time, respectively, and are determined from flow duration curves. An example is given in Fig. 4, where the 3-D response surfaces from Fig. 3 are shown as 2 -D contour plots. In order to enable a comparison between different basins, stream flow is normalized by its 1961-1990 reference value, with contour lines representing stream flow fractions. The high and low flow thresholds are normalized by the (1961-1990) reference stream flow and plotted in the same figure in red.

\subsection{Probabilistic stream flow projections}

The probability of exceeding the above-described thresholds is assessed by superimposing basin-specific equilibrium probability distribution functions (PDFs) onto the RS. PDFs represent changes in 20-yr average climate at decadal steps for the period 2000-2100, in comparison to the 19611990 reference climatology (i.e. 2000-2019, 2010-2029, ..., 

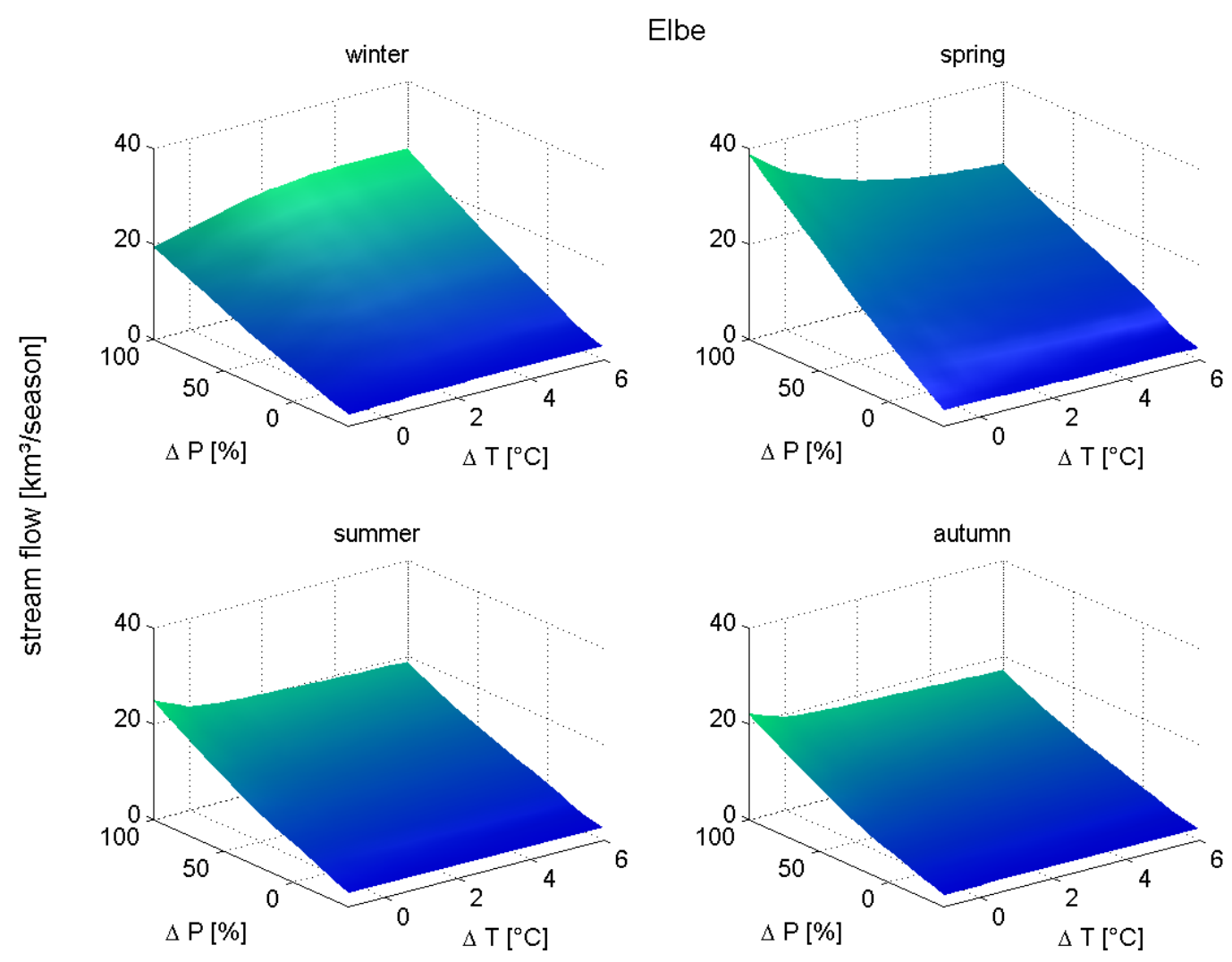

Fig. 3. Response surfaces for the four seasons winter (December, January, February), spring (March, April, May), summer (June, July, August) and autumn (September, October, November) for the Elbe showing the response of stream flow ( $\left.\mathrm{km}^{3} / \mathrm{season}\right)$ to $\mathrm{simultaneous}$ changes in temperature $(T)$ and precipitation $(P)$ in the range $\Delta T\left[-1^{\circ} \mathrm{C} \ldots+6^{\circ} \mathrm{C}\right], \Delta P=[-40 \% \ldots+100 \%]$ relative to the reference period (1961-1990).

2080-2099). The distributions are conditional on the IPCC A1B emission scenario and represent a quantification of the uncertainty associated with major known physical, chemical and biological feedbacks. They are constrained by observations of the climate system, considering structural and parameter uncertainty. The PDFs have been provided by Harris and colleagues from the Hadley Centre, Exeter, UK. Please refer to the article by Harris et al. (2010), for information on the construction and limitation of PDFs.

PDFs are provided as a sample of 10000 points per basin, drawn from the joint distribution. Each point can be considered as equally likely. The probability of exceeding a certain stream flow threshold is hence calculated from the number of points violating the threshold. As an example, in Fig. 5, the 10000 data points are shown for the first 20-yr period 20002019 for the winter season for the Danube basin, depicting the spread in regional response as anomalies relative to the reference climatology. The data is presented as a scatter plot overlain with a contour plot of the kernel-density estimation. The kernel density estimation is used to estimate the probability density function. Note that the distribution of points in the form of a box-shape is caused by Winsorisation at the 1st and 99th percentile. See Harris et al. (2010) for further details. In the following, only kernel densities will be shown. They are superimposed onto the RS in two-dimensional plots with densities shown as contour lines.

\section{Results}

Figures 6 to 8 show examples of seasonal response surfaces of a Northern, Central and Southern European catchment. Red lines mark the high and low flow thresholds. The probability of exceeding these thresholds can be estimated visually by looking at the kernel density contour lines. These are shown in each plot for the first and last of the analysed 20-yr periods (2000-2019 and 2080-2099, respectively). Plots of all 18 analysed river basins can be found in the Supplement. In the following, the results will be further discussed.

\subsection{Analysis of seasonal response surfaces}

In general, three kinds of responses can be distinguished: basins situated mainly in the North of Europe show comparably strong responses to changes in $T$ and $P$, which are 

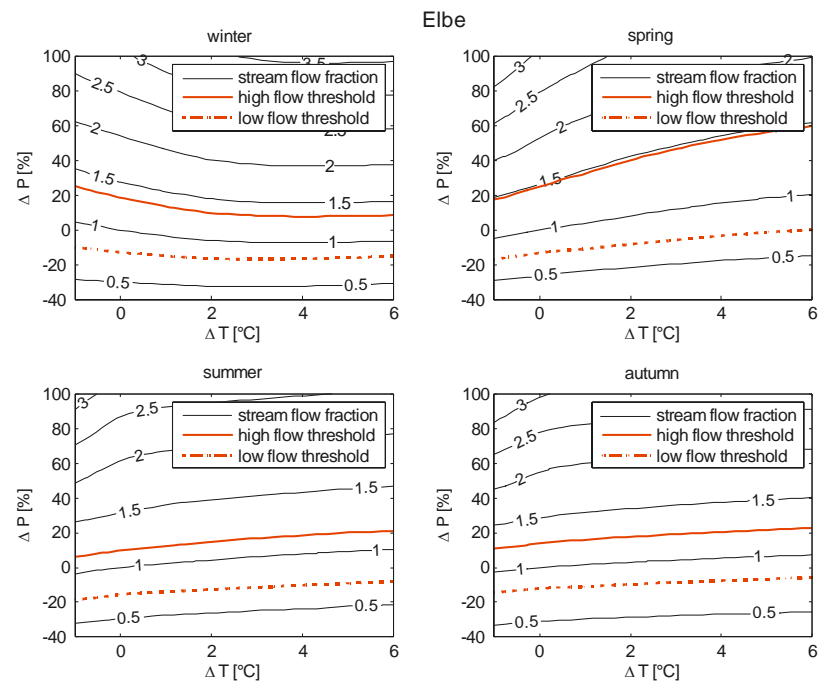

Fig. 4. Response surfaces of stream flow fractions plotted as contour lines (black) and overlain with high and low flow thresholds (red). Values have been normalized by the 1961-1990 reference stream flow value.

evident in all seasons. These are caused by shifts in high and low flows as a consequence of, on the one hand, shifts in the future distribution of precipitation, and, on the other, the sensitivity of stream flow to the onset of snowmelt. Examples are the Glomma basin (Fig. 6) or Angerman basin (not shown), where winter and spring stream flow increase with increasing temperature due to an earlier onset of snowmelt (more pronounced for a simultaneous increase in precipitation). This water is no longer available in spring or summer, when stream flows decrease (more pronounced with stronger temperature increase). A similar phenomenon is also seen for the Danube if winter and spring are compared. Higher flows in winter with increasing temperatures lead to decreased spring flows. This can be seen when comparing the same segments of the winter and spring response surface plots in Fig. 6. Central European catchments, however, show slightly different shapes of RS.

From the five analysed Nordic basins, Vänern Göta shows a much weaker response in comparison to the other four basins (not shown). This can be explained by the fact that a lake (lake Vänern) is situated downstream and evens out most of the upstream stream flow changes. In the other four basins (Glomma, Kemijoki, Angerman, Lule), lakes and wetlands are mainly situated in the upper reaches of the basin, and the buffering effect is therefore less prominent.

The second type of response surfaces is found for basins situated in Central Europe. Most basin responses to $T$ and $P$ changes are still stronger than in Southern European basins, although the RS are shaped differently than in Northern European basins. The influence of the snowmelt is still apparent, although less strong (Fig. 7). The RS are further

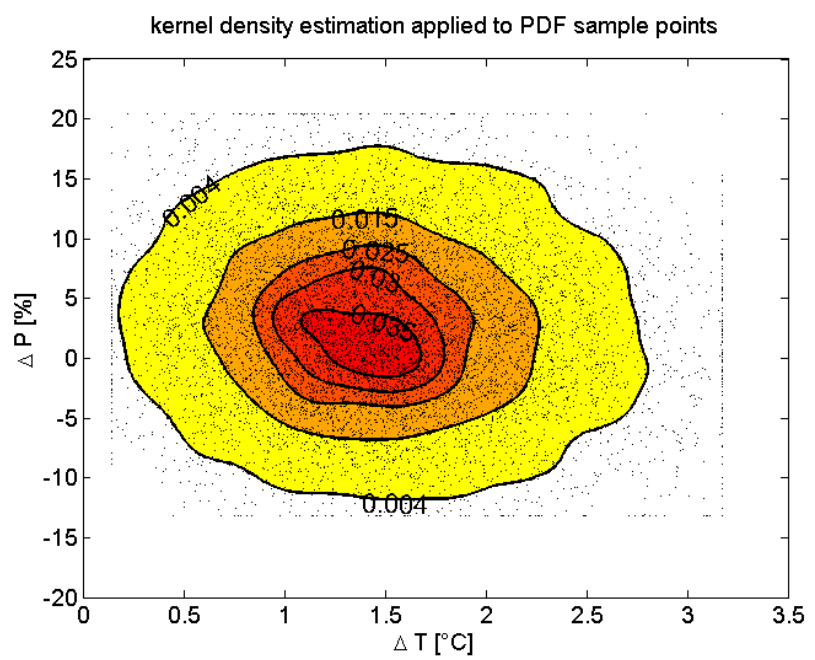

Fig. 5. Example of the 10000 sample data points for the time slice 2000-2019 for the IPCC A1B scenario, drawn from the joint probability distribution function for the Danube, superimposed with the contour lines of the kernel density estimation.

dominated by the shift in precipitation under future climates. For increasing temperature, evaporation takes over as a dominant process and stream flow reactions are less pronounced in that area of the response surface.

The third group is formed by basins in Southern Europe, where responses are less strong and rather linear in all seasons. Here, a more stable flow regime is present, due to smaller seasonal shifts in the distribution of future precipitation, and a higher evaporative demand in general, which prevents additional precipitation to increase stream flow. Examples are Tagus (Fig. 7), or Douro, Tiber and Guadalquivir (not shown).

\subsection{Probabilistic stream flow assessment}

The probabilities for violating seasonal high flow and low flow thresholds are shown in Figs. 9 to 11, again for three sample basins of the three different categories discussed above. Plots for all basins are part of the Supplement. The probabilities for exceeding the thresholds increase steadily over time. A stagnation or even small decline is noticeable in some basins (e.g. violation of the low flow threshold at the Tagus in Fig. 9) towards the end of the century. This, however, can rather be attributed to the fact that the plume of scattered data becomes increasingly larger, and with it the uncertainty for a river basin to reach a certain stream flow state, and not to a projected decrease of climate anomalies towards the end of the 21 st century.

In total, four Northern European basins are very likely to exceed the high flow threshold (probability $>0.9$ ) towards the end of the 21 st century in the winter season (Glomma, Kemijoki, Lule and Angerman), two of them additionally in 

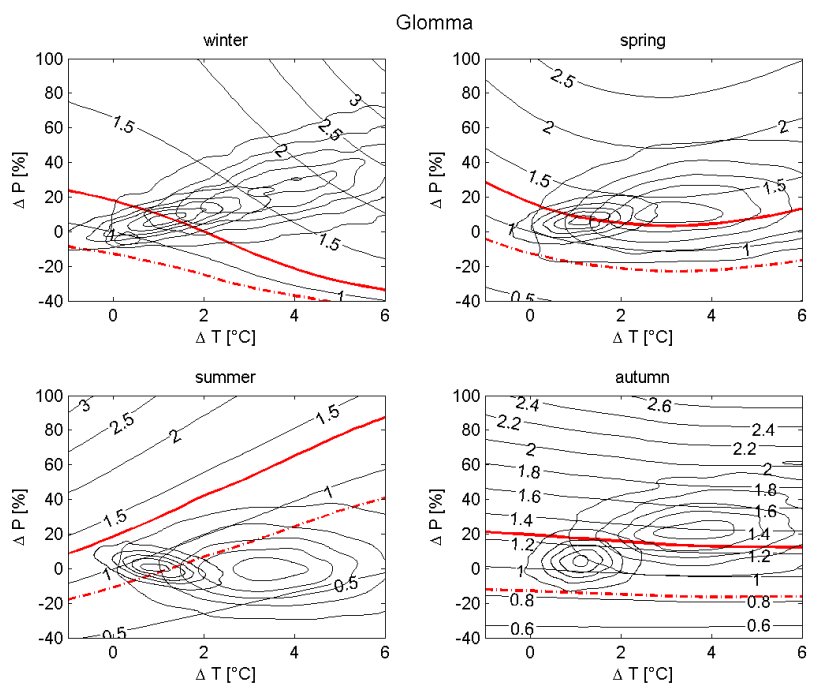

Fig. 6. Seasonal RS of a Northern European catchment (Glomma), with contours of fractional stream flow, high and low flow thresholds (red lines) and kernel density plots of the probability distribution for the first (2000-2019) and last period (2080-2099).
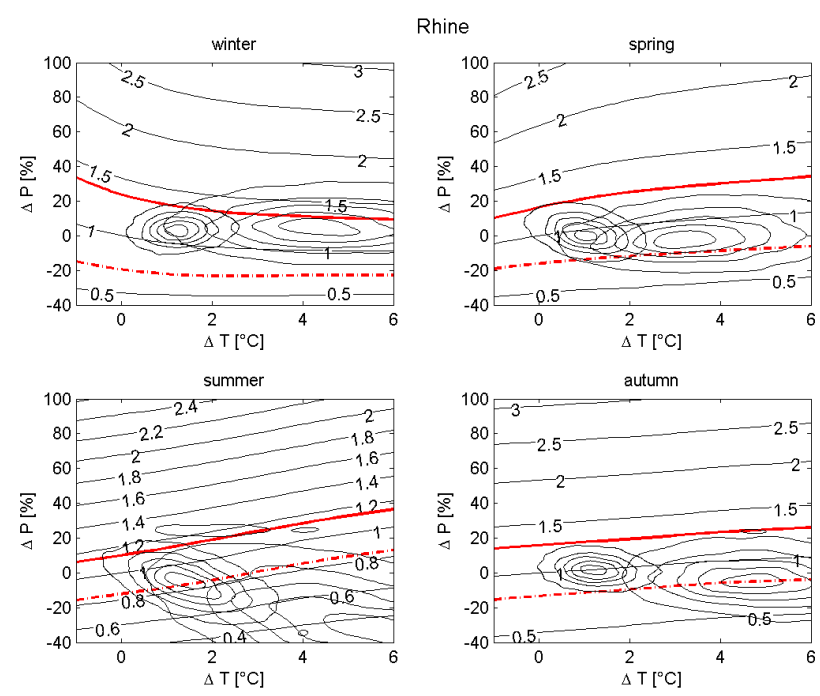

Fig. 7. Seasonal RS of a Central European catchment (Rhine), with contours of fractional stream flow, high and low flow thresholds (red lines) and kernel density plots of the probability distribution for the first (2000-2019) and last period (2080-2099).

more than one season (Lule, see Fig. 8, and Angermann, not shown).

In the Danube (Fig. 9), Rhine, Po, and Tagus basins, summer stream flow will very likely (probability $>0.9$ ) be lower than the low flow threshold. For a total of eight Central and Southern European basins, this is likely (probability between 0.75 and 0.9 ). Low flow thresholds are almost entirely violated in summer, except for Danube (Fig. 9) and Tagus (Fig. 10), where flows below the threshold are additionally encountered in autumn and spring.
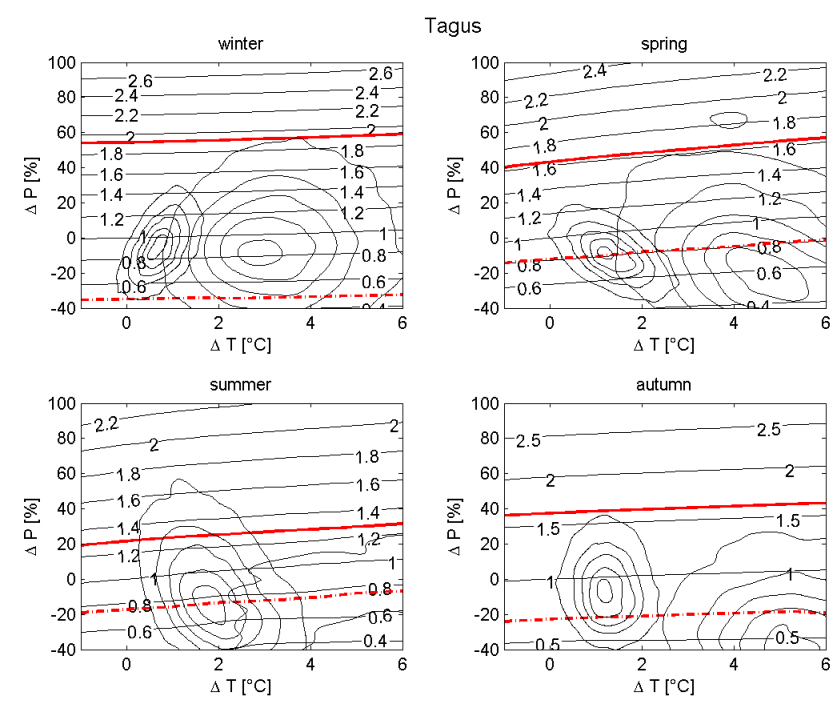

Fig. 8. Seasonal RS of a Southern European catchment (Tagus), with contours of fractional stream flow, high and low flow thresholds (red lines) and kernel density plots of the probability distribution for the first (2000-2019) and last period (2080-2099).

Seven basins might have to deal with intermittent high and low flows in the future, depending on the season. These are Glomma, Kemijoki, Vänern Göta, Angerman, Elbe, Danube (Fig. 9), and Vistula (exeedance probabilities of $>0.5$ considered).

\section{Discussion}

In this study, the hydrological model WaterGAP is used to simulate natural flows. Flow regulation is not considered. The threat of basins violating both high and low flow thresholds could in reality be lower due to an existing flow regulation that levels the stream flow, which is not taken into account here. However, many of these basins are already heavily regulated (Nilsson et al., 2005) and it is questionable, whether current regulation facilities are capable of further reducing the projected increase in seasonal flow amplitude.

The abundance of lakes and wetlands in Northern Europe only becomes visible in the results for the Vänern Göta basin, where it buffers the stream flow response to changes in $T$ and $P$, due to the fact that the Vänern lake is situated downstream. In the other four considered Northern basins, lakes and wetlands are situated mainly upstream, and therefore their buffering capacities are much lower.

It has to be considered that in this approach, the hydrological model is run in a simplified mode, and 30-yr time series of daily flows are averaged to form a single value on the response surface. The strength of this method is that it can be applied to give an overview over an arbitrary number of basins, thus helping to identify hot-spots, offering an opportunity to consider a great number of different thresholds, 

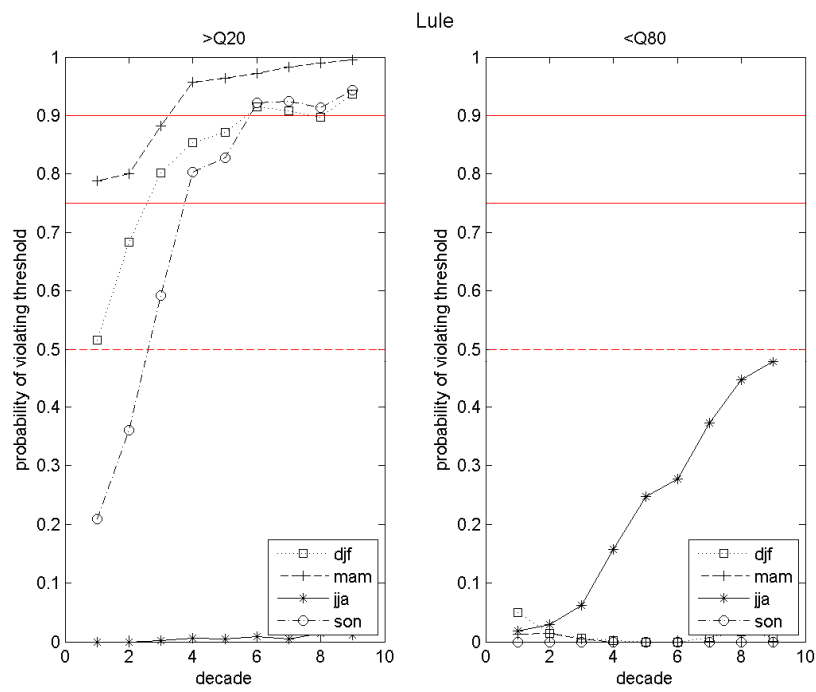

Fig. 9. Threshold exceedance probability for stream flow violating the high flow threshold (stream flow $>Q_{20}$ ) and low flow threshold (stream flow $\left.<Q_{80}\right)$ for each season $(\mathrm{djf}=$ winter, $\mathrm{mam}=$ spring, jja $=$ summer, son $=$ autumn) of the Lule, with decades on the $\mathrm{x}$-axis as follows: $1=2000-2019,2=2010-2029, \ldots, 9=2080-2099$.

emission scenarios and climate models. However, it cannot replace more detailed studies for specific questions in impact sectors that require a higher temporal resolution. Due to the temporal averaging, solely general low or high flow conditions are examined. The approach presented here cannot be used for the prediction of floods or droughts in specific years. Yet, increasing low or high flow conditions do also point towards more frequent single extreme events.

The two examined thresholds have been chosen from a wealth of flow indices that are used at the planning level of water resources development, and environmental flow recommendations (Tharme, 2003). A great number of other thresholds could also be used, allowing an application of the method to more specific impact sectors and basins, such as minimum flow requirements due to basin-specific water uses for industrial, shipping or cooling purposes, or based on water quality aspects, etc. The inclusion of further thresholds is very simple with the approach presented.

Non-covered uncertainty arises from the magnitude of future anthropogenic water abstractions, which influence river flow. Here, water uses were kept constant at current levels (1971-2000). These might be subject to change based on socio-economic and climate change influences. A high probability of low flows occurring during summer in Central and Southern Europe coincides with the season of the highest irrigation demand (Schaldach et al., 2009; Rost et al., 2008; Döll and Siebert, 2002). On the one hand, increasing irrigation requirements in the future could further reduce stream flows, and the demand might not be fulfilled at all, further affecting the agricultural sector and economy of a country. On
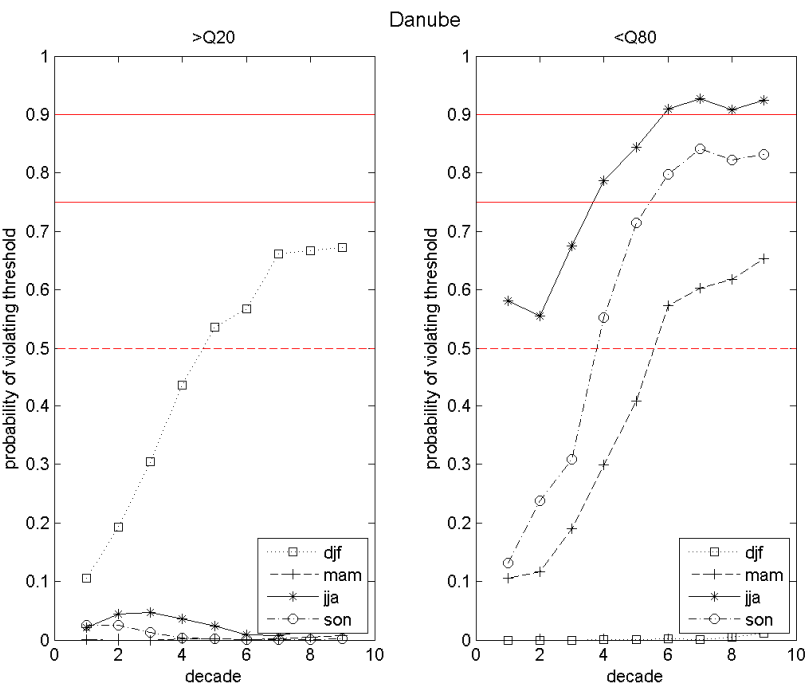

Fig. 10. Threshold exceedance probability for stream flow violating the high flow threshold (stream flow $>Q_{20}$ ) and low flow threshold (stream flow $\left.<Q_{80}\right)$ for each season $(\mathrm{djf}=$ winter, $\mathrm{mam}=$ spring, jja $=$ summer, son $=$ autumn) of the Danube, with decades on the $\mathrm{x}$ axis as follows: $1=2000-2019,2=2010-2029, \ldots, 9=2080-2099$.
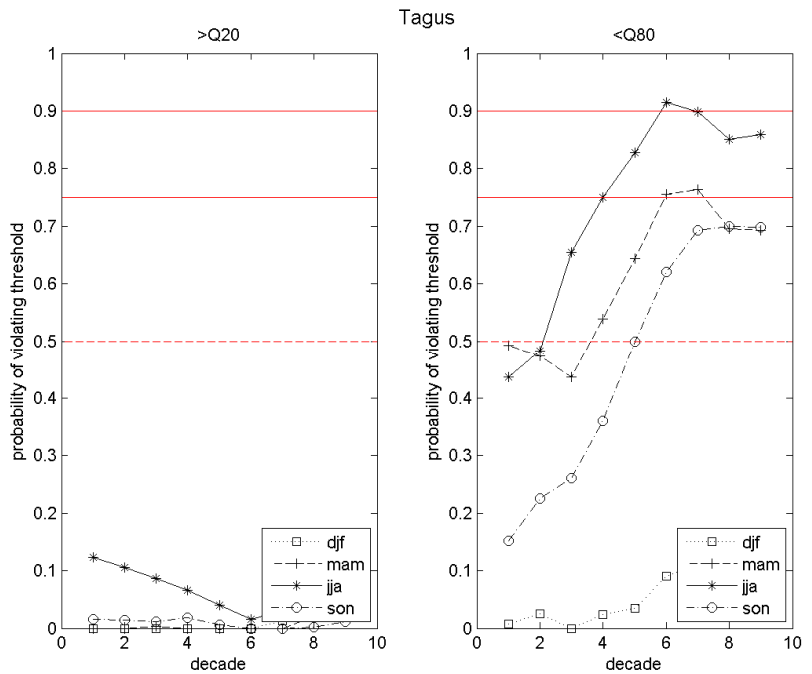

Fig. 11. Threshold exceedance probability for stream flow violating the high flow threshold (stream flow $>Q_{20}$ ) and low flow threshold (stream flow $\left.<Q_{80}\right)$ for each season $(\mathrm{djf}=$ winter, mam $=$ spring, $\mathrm{jja}=$ summer, son $=$ autumn) of the Tagus, with decades on the $\mathrm{x}$ axis as follows: $1=2000-2019,2=2010-2029, \ldots, 9=2080-2099$.

the other hand, management practices could help reduce water use abstractions, by e.g. improved technologies, reduced losses and improved irrigation scheduling to leave more water instream. On balance, these opposing tendencies might cancel out. 


\section{Summary and conclusions}

In this study, a probabilistic assessment of stream flows violating high and low flow thresholds was carried out. The study makes use of probabilistic climate change projections consisting of 20-yr time slices for the 21st century of Harris et al. (2010), to include a greater number of uncertainties by combining response surfaces generated with a hydrological impact model with joint probability distributions of future climate.

It is shown that Nordic basins have the highest probability of violating the seasonal high flow threshold. Four out of five analysed basins have a probability of $>0.9$ towards the end of the 21st century. The violation occurs with the highest probability in winter, but also other seasons are affected. Most Central and Southern European basins (four out of thirteen with a probability $>0.9$ and seven out of thirteen with a probability of $>0.75$ ) reveal a very high probability of violating the low flow threshold in the summer season towards the end of the 21st century. Some basins will have to cope with wider seasonal flow amplitudes, i.e. a violation of the high flow threshold in one and the low flow threshold in the next season, and vice-versa (Glomma, Angerman, Elbe, Danube, and Vistula).

Overall, the method presented here allows the quantification of stream flow exceedance probabilities under consideration of transient climate change up to 2100 . The method is flexible enough to allow the introduction of an arbitrary number of additional thresholds, emission scenarios and climate models. It is a useful tool for the comparison of a great number of basins, while offering an immediate visual picture of possibly large data sets, and can thus help to identify future hot-spots of climate change, where detailed impact analysis might be sensible.

\section{Supplementary material related to this article is available online at: http://www.nat-hazards-earth-syst-sci.net/11/2163/2011/ nhess-11-2163-2011-supplement.zip.}

Acknowledgements. This study was supported by the ENSEMBLES project, funded by the European Commission's 6th Framework Programme through the contract GOCE-CT-2003505539. The authors would like to thank Glen Harris and colleagues for providing joint PDFs at catchment level, as well as Project Partners in WP6.2 for fruitful discussions. The work of the reviewers is also acknowledged.

Edited by: J. E. Olesen

Reviewed by: A. Te Linde and two other anonymous referees

\section{References}

Alcamo, J. M., Döll, P., Henrichs, T., Kaspar, F., Lehner, B., Rösch, T., and Siebert, S.: Development and testing of the WaterGAP
2 global model of water use and availability, Hydrol. Sci., 48, 317-337, doi:10.1623/hysj.48.3.317.45290, 2003.

Alcamo, J. M., van Vuuren, D., Ringler, C., Cramer, W., Masui, T., Alder, J., and Schulze, K.: Changes in Nature's Balance Sheet: Model-based Estimates of Future Worldwide Ecosystem Services, available at: http://www.ecologyandsociety.org/vol10/ iss2/art19/, Ecol. Soc., 10(27), 2005.

Alcamo, J. M., Flörke, M., and Märker, M.: Future longterm changes in global water resources driven by socioeconomic and climatic changes, Hydrol. Sci. J., 52, 247-275, doi:10.1623/hysj.52.2.247, 2007.

Arnell, N. W.: Climate Change and Water Resources in Britain, Clim. Change, 39, 83-110, doi:10.1023/A:1005339412565, 1998.

aus der Beek, T., Voß, F., and Flörke, M.: Modelling the impact of Global Change on the hydrological system of the Aral Sea basin, Phys. Chem. Earth, Parts A/B/C, doi:10.1016/j.pce.2011.03.004, in press, 2011.

Ballester, J., Douville, H., and Chauvin, F.: Present-day climatology and projected changes of warm and cold days in the CNRM-CM3 global climate model, Clim. Dynam., 32, 35-54, doi:10.1007/s00382-008-0371-0, 2009.

Bergström, S., Carlsson, B., Gardelin, M., Lindstrom, G., Pettersson, A., and Rummukainen, M.: Climate change impacts on runoff in Sweden-Assessments by global climate models, dynamical downscaling and hydrological modelling, Climate Res., 16, 101-112, doi:10.3354/cr016101, 2001.

Clausen, B. and Biggs, B. J. F.: Flow variables for ecological studies in temperate streams: groupings based on covariance, J. Hydrol., 237, 184-197, doi:10.1016/S0022-1694(00)00306-1 2000.

Dankers, R. and Feyen, L.: Flood hazard in Europe in an ensemble of regional climate scenarios, J. Geophys. Res., 114, D16108, doi:10.1029/2008JD011523, 2009.

Döll, P. and Lehner, B.: Validation of a new global 30-min drainage direction map, J. Hydrol., 258, 214-231, doi:10.1016/S00221694(01)00565-0, 2002.

Döll, P. and Siebert, S.: Global modeling of irrigation water requirements, Water Resour. Res., 38(4), 1037, doi:10.1029/2001WR000355, 2002.

Döll, P., Kaspar, F., and Lehner, B.: A global hydrological model for deriving water availability indicators: model tuning and validation, J. Hydrol., 270, 105-134, doi:10.1016/S00221694(02)00283-4, 2003.

GRDC: Long Term Mean Monthly Discharges and Annual Characteristics of Selected GRDC Stations, The Global Runoff Data Centre, Koblenz, Germany, 2004.

Hagemann, S., Göttel, H., Jacob, D., Lorenz, P., and Roeckner, E.: Improved regional scale processes reflected in projected hydrological changes over large European catchments, Clim. Dynam., 32, 767-781, doi:10.1007/s00382-008-0403-9, 2009.

Harris, G. R., Collins, M., Sexton, D. M. H., Murphy, J. M., and Booth, B. B. B.: Probabilistic projections for 21st century European climate, Nat. Hazards Earth Syst. Sci., 10, 2009-2020, doi:10.5194/nhess-10-2009-2010, 2010.

Hewitt, C. D.: The ENSEMBLES Project: Providing ensemblebased predictions of climate changes and their impacts, EGGS Newsl, 13, 22-25, 2005.

IPCC: Special Report on Emission Scenarios, Cambridge University Press, Cambridge, 599 pp., 2000. 
IPCC: Climate Change 2007: The Physical Science Basis. Contribution of Working Group I to the Fourth Assessment Report of the Intergovernmental Panel on Climate Change, edited by: Solomon, S., Qin, D., Manning, M., Chen, Z., Marquis, M., Averyt, K. B., Tignor, M., and Miller, H. L., Cambridge University Press, Cambridge, UK and New York, USA, 996 pp., 2007.

Lehner, B., Döll, P., Alcamo, J. M., Henrichs, T., and Kaspar, F.: Estimating the impact of global change on flood and drought risks in Europe: A continental, integrated analysis, Clim. Change, 75, 273-299, 2006.

Middelkoop, H. and Asselman, N.: Impact of Climate and Land Use Change on River Discharge and the Production, Transport and Deposition of Fine Sediment in the Rhine basin - a summary of recent results, in: Long Term Hillslope and Fluvial System Modelling, edited by: Lang, A., Dikau, R., and Hennrich, K., Springer, Berlin, Heidelberg, 157-181, 2003.

Mimikou, M., Baltas, E., Varanou, E., and Pantazis, K.: Regional impacts of climate change on water resources quantity and quality indicators, J. Hydrol., 234, 95-109, doi:10.1016/S00221694(00)00244-4, 2000.

Mitchell, T. D. and Jones, P. D.: An improved method of constructing a database of monthly climate observations and associated high-resolution grids, Int. J. Climatol., 25, 693-712, doi:10.1002/joc.1181, 2005.

Monk, W. A., Wood, P. J., Hannah, D. M., and Wilson, D. A.: Selection of river flow indices for the assessment of hydroecological change, River Res. Appl., 23, 113-122, doi:10.1002/rra.964, 2007.

Murphy, J. M., Sexton, D. M. H., Jenkins, G. J., Booth, B. B. B., Brown, C. C., Clark, R. T. C., M., Harris, G. R., Kendon, E. J., Betts, R. A., Brown, S. J., Humphrey, K. A., McCarthy, M. P., McDonald, R. E., Stephens, A., Wallace, C., Warren, R., Wilby, R., and Wood, R.: UK Climate Projections Science Report: Climate change projections, Met Office Hadley Centre, Exeter, UK, 2009.
Nikulin, G., Kjellström, E., Hansson, U. L. F., Strandberg, G., and Ullerstig, A.: Evaluation and future projections of temperature, precipitation and wind extremes over Europe in an ensemble of regional climate simulations, Tellus A, 63, 41-55, 2011.

Nilsson, C., Reidy, C. A., Dynesius, M., and Revenga, C.: Fragmentation and Flow Regulation of the World's Large River Systems, Science, 308, 405-408, doi:10.1126/science.1107887, 2005.

Olden, J. D. and Poff, N. L.: Redundancy and the choice of hydrologic indices for characterizing streamflow regimes, River Res. Appl., 19, 101-121, doi:10.1002/rra.700, 2003.

Rost, S., Gerten, D., Bondeau, A., Lucht, W., Rohwer, J., and Schaphoff, S.: Agricultural green and blue water consumption and its influence on the global water system, Water Resour. Res., 44, W09405, doi:10.1029/2007WR006331, 2008.

Schaldach, R., Flörke, M., and Lapola, D.: A model-based assessment of the potential role of irrigated cropland for biogas production in Europe, Adv. Geosci., 21, 85-90, doi:10.5194/adgeo21-85-2009, 2009.

Tharme, R. E.: A global perspective on environmental flow assessment: Emerging trends in the development and application of environmental flow methodologies for rivers, River Res. Appl., 19, 397-441, 2003.

Vörösmarty, C. J. and Sahagian, D.: Anthropogenic disturbance of the terrestrial water cycle, Bioscience, 50, 753-765, 2000.

Weiß, M. and Alcamo, J.: A systematic approach to assessing the sensitivity and vulnerability of water availability to climate change in Europe, Water Resour. Res., 47, W02549, doi:10.1029/2009WR008516, 2011. 